\title{
e-REAL: Enhanced Reality Lab
}

\author{
http://dx.doi.org/10.3991/ijac.v7i3.4033 \\ Fernando Salvetti and Barbara Bertagni \\ Logos Knowledge Network, Bern, Switzerland and University of Milan Bicocca, Milan, Italy
}

\begin{abstract}
REAL - enhanced reality lab - is a fullyimmersive and multitasking environment, designed to experience challenging situations in a group setting, engaging all participants simultaneously on different levels: with peers, thematic experts, and learning facilitators, both on-site, and remotely. e-REAL is a lab based on visual thinking and knowledge visualization, facilitated by enhanced (or augmented) reality tools. It is a highly interactive and face-toface lab that promotes proactive data and information research (everything is available, but learners have to actively look for it) - allowing knowledge sharing with remote teams, and integrating training on soft skills with those that are technical and specialized.
\end{abstract}

Index Terms-Visual thinking, knowledge visualization, immersive learning, augmented reality tools, new media in education.

\section{INTRODUCTION}

e-REAL - enhanced reality lab - is a fully-immersive and multitasking environment, designed to experience challenging and problem-based situations in a small group setting, while engaging all participants simultaneously on different levels. This includes peers, thematic experts. and learning facilitators, both on-site and remotely.

e-REAL is a lab based on visual thinking and knowledge visualization, facilitated by enhanced (or augmented) reality tools. The style of learning reduces time spent in lectures, in exchange for a dynamic and immersive, interactive and multimedia environment. Three representative classrooms are shown in Figures 1-3 and others can be found at www.e-real.net.

e-REAL focuses on making the intangible more tangible. It is a highly interactive and face-to-face lab that promotes proactive data and information research (everything is available, but learners have to actively look for it) allowing knowledge sharing with remote teams, and integrating training on soft skills with those that are technical and specialized.

Visual thinking, digital technologies, and knowledge visualization are transforming the way in which people learn, by opening up new opportunities for immersive training, as well as serious gaming. Similar to being immersed within a videogame, people are challenged by facing real cases within complex scenarios that present a "more than real" wealth of information - this occurs while the many levels of the situation are made available simultaneously.

Learners can have a complete overview of a case, access relevant information, take a look at professional literature and consult strategic guidelines. They will find everything needed to make a decision, such as information,

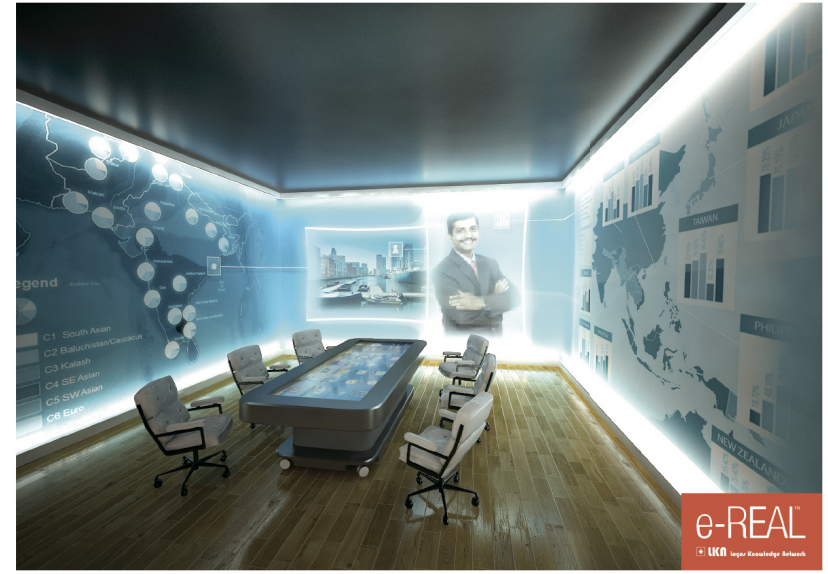

Figure 1.

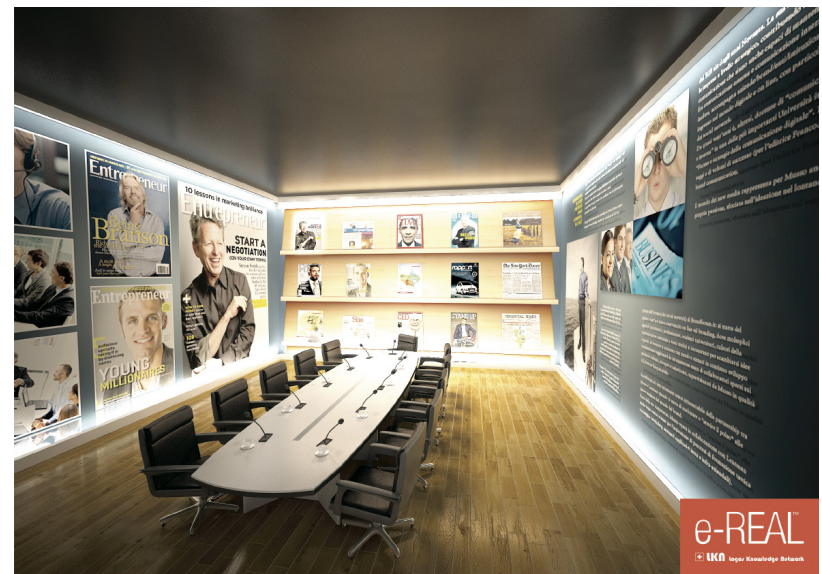

Figure 2.

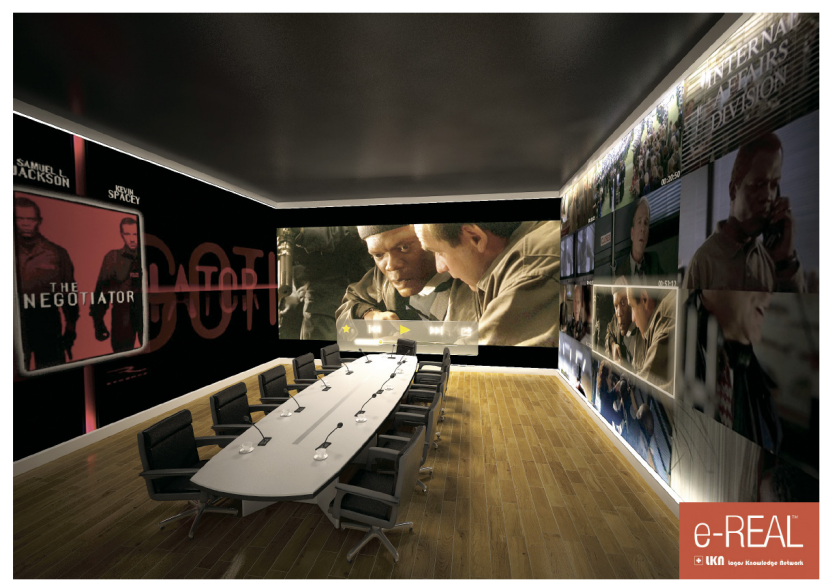

Figure 3 
benchmarks, and so on. So many skills are fostered: both behavioral and cognitive ones, as well as metacognitive skills.

Accordingly with our vision, fostering cognitive skills as well as metacognition - jointly with behavioral and technical skills - is very relevant because it helps people to perform many tasks more effectively. In particular, metacognition - "cognition about cognition," or "knowing about knowing" - is essential, because the buzzwords of the times are: creativity, innovation, cross-cultural intelligence, and flexibility. Metacognition can take many forms; it includes knowledge about when and how to use particular strategies for learning or for problem solving. Strategies for promoting metacognition include: selfquestioning (e.g. "What do I already know about this topic? How have I solved problems like this before?"), thinking aloud while performing a task, and making graphic representations (e.g. concept maps, flow charts, semantic webs) of one's thoughts and knowledge.

People, who are high achievers in academic or professional learning domains, also exhibit higher levels of metacognitive knowledge (awareness and strategy) about the same domain, and have developed greater abilities in selfregulation. Some psychologists hypothesize that metacognition is used as a survival tool, which would make metacognition the same across cultures [1]. So, fostering metacognition through a learning environment that is very immersive and quite futuristic is an added value for eREAL.

Within e-REAL, skills and talents can be developed in order to create the next generation of global innovators and entrepreneurs, as well as good professional people.

\section{ENHANCING INTELLIGENCE BY VISUAL THINKING}

"It is possible to teach every branch of human knowledge with the motion picture." Observed Thomas Edison in 1913 - predicting that books would soon be obsolete in the classroom [2]. In fact, motion pictures have had little effect on education and training. The same, until recently, was true of computers. Today, in most of the world, learners use computers to do research and type essays at every stage; from primary to post-graduate education, or vocational training. But the core of the system has changed little since the Middle Ages. A "sage on a stage" teacher, still spouts "lessons" to rows of students.

Now, we live within a networked society, and, at last, a revolution is under way due to a number of big changes that are emerging at the same time: high-speed mobile networks, cheap tablet devices, the ability to process huge amounts of data cheaply, sophisticated online gaming, and adaptive-learning software, "stellar" contents available for free, and "superstar" lecturers and experts are remotely available.

At its heart is the idea of moving from a "one-size-fitsall" education, to a more personalized approach, with technology allowing true human-centric processes to enhance learning by utilizing augmented reality tools. The job of the classroom's teachers and trainers, at every education and training stage, will move from orator to coach and learning facilitator, with adaptive computer programs and augmented reality tools allowing each learner to be actively engaged at his or her own pace.

e-REAL is the place where it is possible to teach every branch of human knowledge with motion pictures, as well as with $3 \mathrm{D}$ images, movies and augmented reality tools. Visual thinking, digital technologies, and knowledge visualization are transforming the way in which people learn by opening up new opportunities for immersive training. Much like being immersed within a videogame, people are challenged by facing real cases within complex scenarios that present a "more than real" wealth of information. This is because the many levels of the situation are made available simultaneously.

As information technologies evolve, so do the possibilities for more immersive learning and teaching techniques. e-REAL is using cutting edge technologies to create both a virtual, and a physical environment in a room, which immerses people in real life situations (e.g. negotiation with a client, opening a new shop abroad, crisis management or decision making within a networked virtual team), with possibilities to interact simultaneously with peers, tutors and learning facilitators, thematic experts and colleagues (both on-site and remotely), as well as consulting literature, records and other written information (that are available as multimedia content).

e-REAL submerges learners in an immersive reality where the challenge to be tackled is created by sophisticated, interactive computer animation in three dimensions, and holographic projections. It further includes live and real time interaction with peers, trainers, tutors, facilitators and mentors. This adds a very important social component that enhances learning outputs, as well as metacognitive processes (and skills).

The primary concepts and issues of a particular case can be dealt with by visualizing them with the use of holograms (to be seen without 3D glasses or any particular tool), on big screens, or by projecting them directly on walls, ceilings and floors. By moving the body, or with a flick of the hands, people can experiment with dynamic images, sound and vision, including holograms and 3D visualizations; all creating a profound emotional impact. So, it's quite a "futuristic" educational environment; very fitting with tertiary education and vocational training; and is an ideal environment to foster innovation and entrepreneurship.

In Figure 4, a representative classroom is shown, highlighted with some commentary to provide a deeper understanding in regards to some of the tools available in the immersive room.

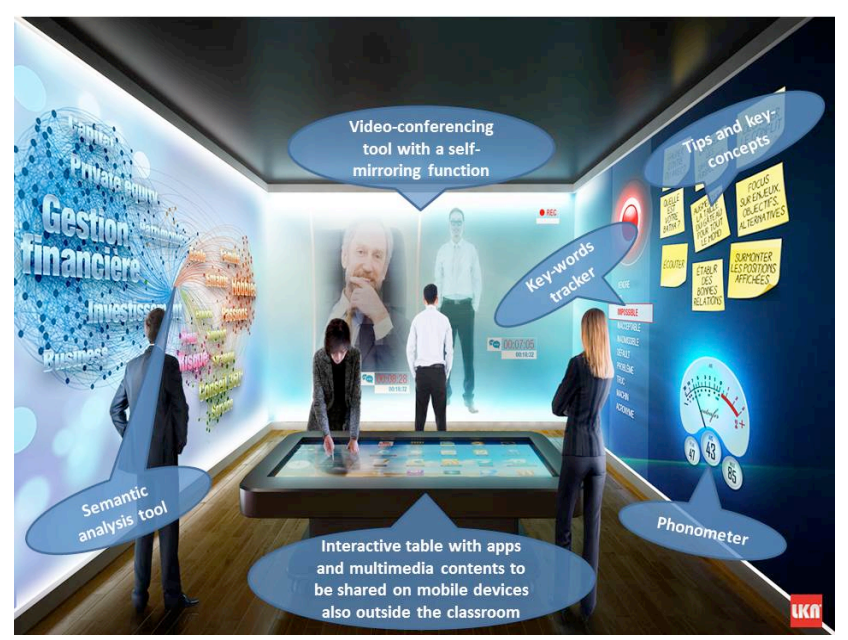

Figure 4. 
The process of "learning by doing" within an immersive lab, based on knowledge visualization of interactive surfaces (walls, mobile devices, electronic tables, etc.), leaves the attendees with a profound and memorable experience.

Attendees are challenged both cognitively and behaviorally in a fully-immersive and multitasking learning environment. So, e-REAL is an ideal educational environment in order to foster technical and soft skills, that are competency related; as well as cognitive; and metacognitive skills.

Moreover, e-REAL is an environment that immerses the learners in an "augmented" reality where real life situations can be really lived (not only simulated), and the necessary lessons learned without the disadvantage of a negative impact in case of mistakes. So, e-REAL is very good with regards to constructivism in education, which showcases that learning is a process of social action and engagement, involving different ways of thinking, doing, and communicating [3]. Learning is a form of participation in social environments aimed at "co-constructing" knowledge: learning is an interactive, highly contextual process that leads to new interpretations of the world, and creates a "social fabric." All of this has some very significant implications for the design of learning architectures [4].

By utilizing e-REAL, a myriad of skills are fostered: both behavioral and cognitive, as well as metacognitive skills. Finally, technical skills are also honed, because it is mainly by fostering technical and job-related skills that soft-skills are developed as well.

Another relevant added value of e-REAL is that an immersive lab can be built both as a permanent installation, and as a portable setting, making the delivery incredibly flexible. e-REAL can be put in place virtually anywhere in the world. Technically, the only requirements are electricity (a few KWs in a basic configuration of the lab) and an internet connection, due to the fact that e-REAL is not a large consumer of bandwidth. So e-REAL can be shipped, and installed all around the world (from downtown to a desert, on a boat, or on a truck).

e-REAL is unique in the market because the projecting system is based on short-throw projectors, while other immersive rooms devoted to educational purposes are currently developed using rear-projection systems that require screen-walls - which are both expensive and mostly suitable to permanent installations.

Fgures 5-7demonstrate the basic portable configuration, as well as the elements to be shipped and put in place for an e-REAL lab.

\section{IMMERSIVE LEARNING: THE INTELLIGENCE OF PERCEPTION}

e-REAL is an immersive learning environment. As we submerge ourselves in it and our bodies (as well), we will feel some sensation of what our ego may not necessarily be rationally and linguistically aware of. Learning happens through being immersed in a context. Even more relevant learning happens by encountering differences. Living in technologically evolved cities and rural areas, frequently visiting increasingly interconnected urban and rural landscapes, electronically navigating and travelling for business and pleasure; we need sufficiently fluid categories to understand the versatile realities of the multiple

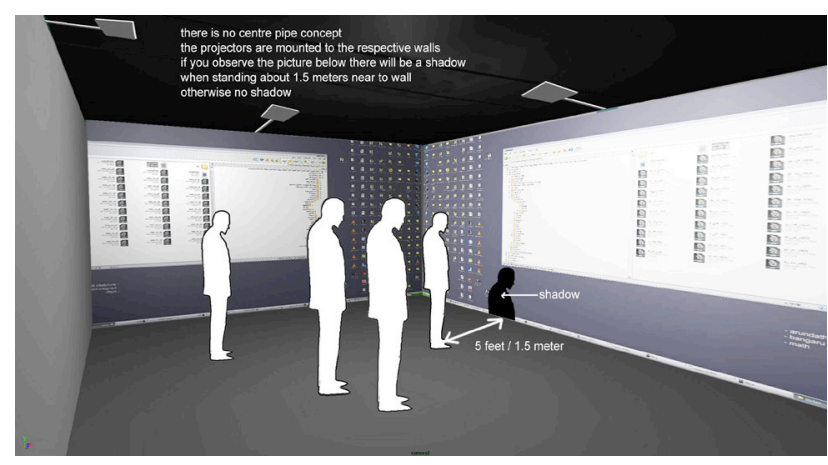

Figure 5.

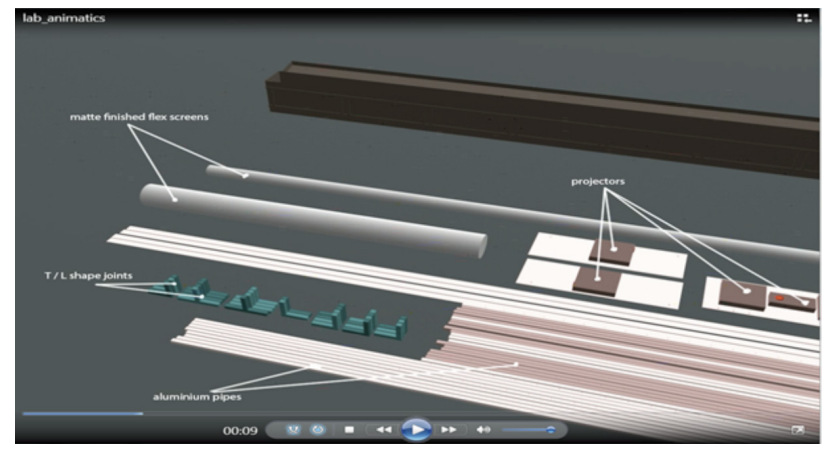

Figure 6.

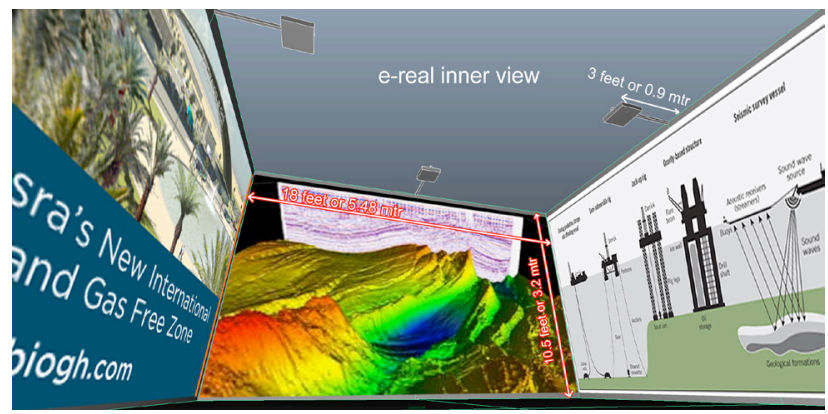

Figure 7.

worlds we live in, as well as to explore the expressive, cognitive, and imaginative possibilities of our times [5].

e-REAL is the union of perception and thought; which is not merely a specialty of the arts. It includes everything that you see, breathe, smell, and touch in your experience and your training. When we design an educational environment, we try to pay particular attention to those "soft" factors that are perceptions, backgrounds, sensations, relational situations, or emotions. Our departure points can be summarized by the title of a book by Maurice MerleauPonty: The Primacy of Perception [6]. Experience is lived and perceived as a focal point and as a key crossroads from which to start structuring those "hard" aspects; and molds, the shaping architecture that connotes a specific training environment.

Within e-REAL, the idea of learning processes as discursive construction comes into its own [7]. Such a learning environment is characterized by the primacy of perception, backgrounds, and emotions, in counter position to a well-founded tradition based not only on an epistemology and a vision of science that is rather naïve (positivism, as "neo," or not as it may be), but also as a much criticized "metaphysical" thesis relating to human beings: dualism 
(as Cartesian, or not, as it may be) and the clean mindbody separation. The body - "physical substance" - with its chemical, pneumatic, mechanical and electrical mechanisms; the mind with its thoughts, sentiments, memories and images; made up of a totally separate "mental substance."

Even if the Cartesian body-mind dualism historically lost its attraction very early on, the notion that mental life is "internal," separate from behavior, which is "external," survived much longer and can still be found today in many psychological, pedagogical, and andragogical approaches. With the consequences - often experienced by those who attend schoolrooms, universities, professional and corporate training centers and business schools - of uniting and managing impoverished, simplified models and conceptual human action that cannot be used in the dense and polysemic dynamics of our daily lives. Perhaps it is no coincidence that we still often bring into account learning environments that, doing a little archaeology of knowledge, we could trace back to the model of the Panopticon, described by Jeremy Bentham, or rather prison (and then hospital, factory or learning institutes), "that shows everything" thanks to the spoke shape of the building: an environment where ideally a single observer may watch everything all the time, adding to the perceptions of the inmates (or patients, workers, students), a sort of omniscience and generalized control by the guardian [8] (Figure 8).

This occurs in an environment - the Panopticon - where learning is conceived as a passing of information from the lecturer to the student, following a communicative process that tends to be one-way (top-down), and within which the "retroactions," feed-back (bottom-up), take on the role of interrogations. Panoptism is a philosophy, and a visionguide. The discipline as a base assumption of the psychopedagogical procedures; taylorism (and its many "neo" variations) as an organizational model [9]. But the Panopticon is not exactly the type of benchmark to look towards for inspiration, unless you wish to "re-edit" Charlie Chaplin in "Modern Times," or any other form of neotaylorism.

We live in increasingly 2.0 and 3.0 worlds, where cooperative learning interaction, that is not too structured, and is a little centralized, helps a lot, in terms of flexibility and enrichment of the individual and organizational cognitive maps. The supremacy of Panopticon, of the uniform look; single disciplinary; and disciplining educational model, is better replaced by the supremacy of perception, individual points of view, and backgrounds as key dimensions from which to start to build learning systems and environments that can help us to understand the varieties of social and working realities, in which we live; the plurality of our belongings; and the ways of acting in different local worlds in which we live, study and work (like within the below Escher's masterpiece (Figure 9)).

We should consider both educational environments, as well as the human mind, to be complex systems. In particular, the human mind works as a meeting point for a wide range of structuring influences whose nature may only be represented on a much larger canvas than that provided by the study of individual organisms. And therefore, we should remember that each one of us lives many different discussions, each of which has its own set of meanings. Some of these discussions may be put into conflict among themselves, necessitating a negotiation and an adjustment to try and make them compatible. The discussions regard symbolic interactions, as well as conventions and relationships, in which these same interactions are bound by informal rules, and are interconnected to each other in ways that reflect that which Michel Foucault called "the order of things." People operate continually in the middle of evaluative and interpersonal influences that shape and manage their activities. People are "agents" who must produce their own constructive interpretations and the expressive acts starting from the contexts in which they are rooted and within which we all live, move, and realize our being.

What we need - in universities and business schools, but above all in public and private organizations, active both in profit markets as well as in non-profit contexts are new ways of thinking, which are able to process peculiarities, individualities, oddities, discontinuities, contrasts, and singularities. Ways of thinking that are able to understand the variety, and plurality of belonging; and ways of being part of the many local worlds in which we live, study and work. We need to learn how to learn a potentially relativist (but not destructive or nihilistic), relational and self-aware thought that knows its requirements, and that is left unsaid. A thought that is able to consider the cognitive restraints that make it up; that sometimes command and control it blindly and fideistically; a thought that is aware that knowledge is a mélange of rationality and rationalization; of true and false intuition, inductions, syllogisms and paralogisms, ways of saying and doing things, personal opinions and shared beliefs [11].

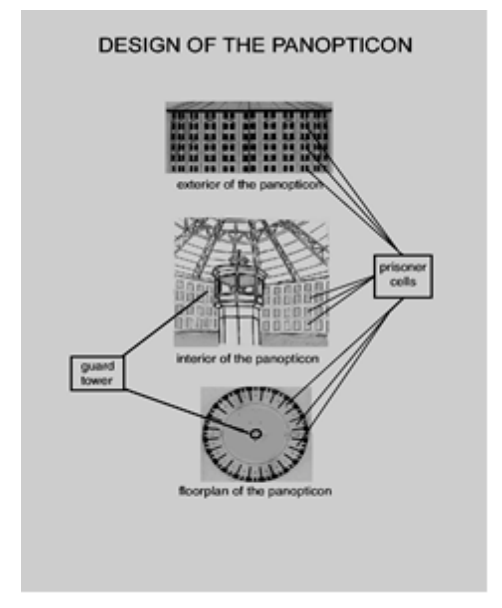

Figure 8.

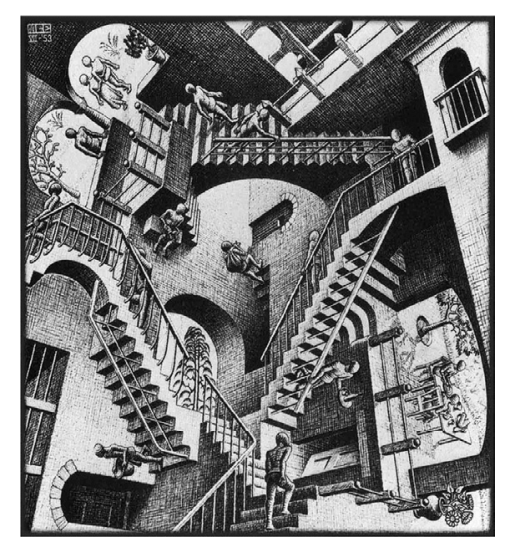

Figure 9. 


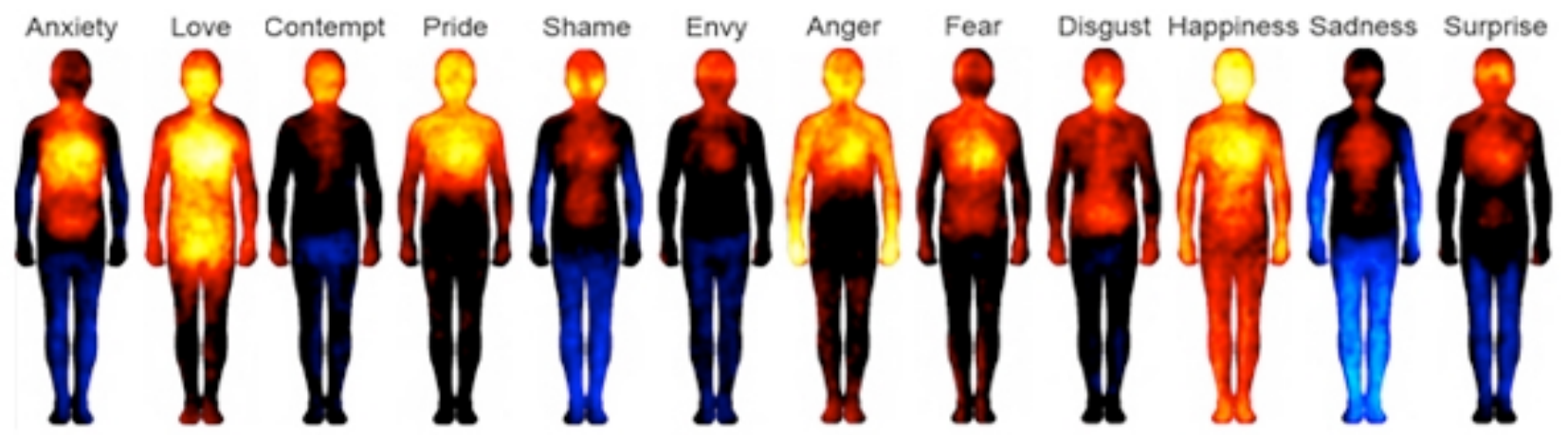

Figure 10.

Starting with the study of perception, Merleau-Ponty reaches the conclusion that the body is not just a "thing" (the Cartesian res extensa), but is also the necessary condition of experience: the body makes up the perceptive opening to the world. The primacy of perception means the supremacy in experience, in the moment in which the perception takes on an active and constitutive role. Recently, researchers from Aalto University have revealed how emotions are experienced in the body (Figure 10). Emotions adjust our mental and bodily states to cope with the challenges detected in the environment. These sensations, arising from bodily changes, are an important feature of our emotional experiences [12].

Emotions shape our experiences, our interactions, and our decisions. They adjust not only our mental, but also our bodily states. In this way, emotions prepare us to react swiftly to danger, but also to opportunities, such as pleasurable social interactions present in the environment.

It is the richness of our emotions and our capacity to have feelings, as well as to think things through, and to reason, which makes us unique as a species. Emotions set the tone of our experience and give life its vitality. They are internal factors that can energize, direct and sustain behavior [13].

At the same time, we often respond emotionally to events and situations that we believe make demands on us we cannot meet - either because we don't have the necessary abilities or resources, or because they force us to make very difficult choices and decisions. Those negative kinds of events and situations are commonly considered to be stressful.

Understanding our emotional reactions is an e-REAL's primary goal. There are many tools available within the lab that are aimed at making people more aware regarding the different emotions they are experiencing - primarily by linking the subjective experience of emotions to associated behavior and physiological changes involving the autonomic nervous system (ANS) and the endocrine system, as well as by monitoring the interpersonal effects of facial expressions, tone of voice and body postures (verbal and not-verbal communication: VC and NVC).

Knowing that we are affected in many ways as well by other people's emotions and emotional expressions, some of the tools currently in use within e-REAL are aimed at focusing on the social context that frames the emotional phenomena. Because emotions adjust our mental and bodily states to cope with the challenges detected in the environment, within e-REAL, we deal with both relevant physiological specificity and people's interpretation of their own emotions.

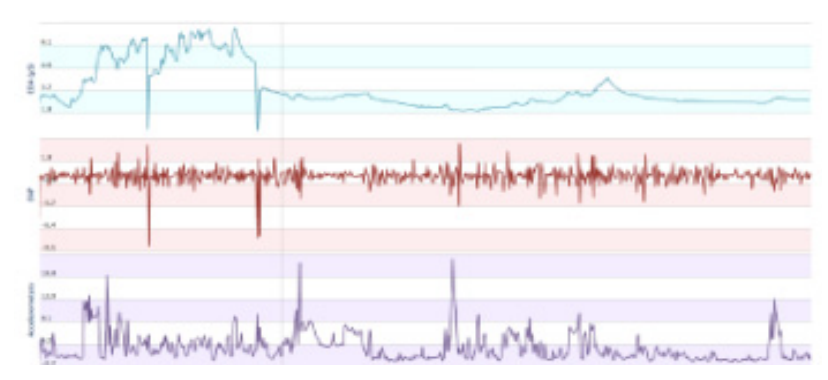

Figure 11.

We are used to working with a number of tools in order to monitor physiological signals in real time, to track people's stress, and other biometrics, to capture facial expressions; analyzing the correlated emotional answers. At the same time, other tools are usually staged in order to do semantic and conversational analysis, to highlight and enumerate some very relevant words (suggested or "forbidden"), to track tone and volume of the voice, as well as pace and pauses. Moreover, we utilize video monitoring and recording of facial expressions and body language, activating many times a mirroring function to foster people's awareness.

In summary: Emotions, visual and perceptual thinking are central within e-REAL. Concepts that take shape, as well as emotions, become part of the discursive scenario thanks to several tools from cutting-edge discoveries in the neurosciences.

\section{ENHANCING MULTIPLE INTELLIGENCES WITH E-REAL}

With powerful tools and enhanced reality resources within the e-REAL labs, people improve their abilities and skills. e-REAL is based on cutting-edge research in the neurosciences. "It's not how smart you are, but how are you smart that matters" - says Gardner [14]. An intelligence is an ability to solve a problem or fashion a product that is valued in one or more cultural settings. This is the way e-REAL is conceived and allows skill development: both soft skills - as personal attributes that enhance an individual's interactions, job performance and career prospects - and hard skills, which encompass a person's skill set and ability to perform a certain type of task or activity.

e-REAL also enables effective cooperative learning based on teamwork and knowledge sharing on a peer-topeer basis, visualizing knowledge and know-how in order to simplify the complexity of the real world - making the "intangible" more tangible. Learning also happens with the "extended mind." Our mind is the result of an ex- 
PAPER

change process with other people and the external environment. The separation between the mind, the body and the environment, is an unprincipled distinction. Since external objects play a significant role in aiding cognitive processes, the mind and the environment act as a "coupled system." This coupled system can be seen as a complete cognitive system of its own. In this manner, the mind is extended into the external world.

In everyday conversation, the emphasis is usually on what is learned (the end product), such as learning to drive a car or to manage an interview. But when psychologists and other learning experts use the term, their focus is on the process: how the learning takes place. Learning is a hypothetical construct: it cannot be directly observed, but only inferred from observable behavior - knowing that learning normally implies a fairly permanent change in a person's behavioral performance as a result of experience [15].

The last several decades have seen a large increase in knowledge of the underlying biological mechanisms that serve learning and memory. The insights gleaned from neurobiological and cognitive neuroscience experimentation in humans, and in animal models, has identified many of the processes at the molecular, cellular and systems levels that occur during learning, and the formation, storage and recall of memories. Moreover, with the advent of noninvasive technologies to monitor patterns of neural activity during various forms of human cognition, the efficacy of different strategies for effective teaching can be compared. Considerable insight has also been developed as to how to most effectively engage these processes to facilitate learning, retention, recall and the effective use and application of learned information [16].

Neuroscientists have defined with increasing precision the various molecular signaling pathways within and between neurons that play a role in learning. In addition, there are equally impressive advances in systems neuroscience to analyze the properties of large-scale neural networks that contribute to learning in the brain of mammals. The application of computational and quantitative behavioral approaches combined with functional brain imaging has revealed strategies employed by human brains to acquire, store and retrieve information in a variety of tasks and settings.

e-REAL is a place where the application of this knowledge to the pedagogy of education and training is happening most effectively in regards to guiding learners to assimilate, comprehend, retain, access, and apply foundations, principles, reasoning skills and necessary facts. There are many types of learning, including various forms of non-associative and associative learning, perceptual learning, and motor learning. Thus, there are considerable opportunities for the integration of current knowledge about the biology of learning with educational strategies.

In the first relevant stage, regarding the molecular and cellular basis of learning, we know that, although memories are generally considered as stable and precise representations of past experiences, they are often anything but that. Memory is a dynamic process where the information represented is subject to our personal experiences; the context of the learning environment; subsequent events; levels of attention; stress; and other factors, such as mnemonic bindings.
So, learning leads to functional and structural changes in the interconnected cellular networks between neurons (synapses) at a variety of sites throughout the central nervous system; first in areas of the brain associated with the formation of new memories. Consequently, a widely shared hypothesis is that there is a direct link between the strength and repetition of the information to be learned, and the persistence of the changes in the nervous system that accompany the learning. For example, repeated activation of neuronal pathways participating in learning with appropriately spaced trials, leads to a cascade of molecular signals that are different, and more persistent than those that accompany briefer or fewer trials [17].

The functional changes in the effectiveness of communication between individual neurons, and networks of neurons, are also accompanied by substantial changes in the structural circuitry of the brain, once thought to be hard-wired in adults. Since the 1980s, advances in optical imaging technologies in the living brain have demonstrated this process of growth, retraction and modifying connectivity between neurons. Moreover, the mature brain can generate new neurons. Such neurogenesis occurs in the dentate gyrus of the hippocampus, although the functional implications of these new neurons, and their potential contribution to learning and memory formation remain to be determined. In addition to molecular and cellular approaches to describe the workings of the underlying hardware changes that occur in the brain during learning, and the formation of memories, there has also been considerable progress in the higher order, human-based studies of cognition, including learning and memory, through the application of functional magnetic resonance imaging (fMRI) of the living brain, combined with computational modeling to elucidate the strategies and underlying neural processes that subserve these functions in humans. An opportunity and challenge for evaluating differing teaching methods is to use fMRI under highly constrained behavioral regimes in interactive settings to directly observe the neural processing architecture and efficiency of these networks during learning .

Many features of the biology of learning have been validated using the biologically based technologies described above, along with behavioral testing. Accordingly, with the seminal study by Friedlander, Andrews, Armstrong, Aschenbrenner, Kass, Odgen, Schwartzsein and Viggiano [19], we identify the following key aspects of learning that we expect can be incorporated into effective teaching paradigms in multiple ways.

- Repetition: Teachers have long appreciated the value of repetition, and revisiting the same topic from multiple perspectives. Learning theory and the neurobiology of learning and memory, suggest that going deeper is more likely to result in better retention and depth of understanding. With repetition or planned redundancies, many components of the neural processes that are engaged become more efficient (less energy used, more rapid neural execution, offloading to lower-order pathways leaving higher-order pathways available for additional cognitive processing). There is also considerable evidence for the importance of appropriate spacing of repetitive trials [20].

- Reward and Reinforcement: Reward is a key component of learning at all stages of life, and in all species, including humans. Most parents are familiar with the 
outcome from rewarding and celebrating a child's successes and "good behaviors." There is a rich biological understanding of detection of associations, particularly between temporally contemporaneous events. The underlying mechanisms of these associations are known, including the existence of molecular coincidence detectors. Moreover, the brain's intrinsic reward system plays a major role in reinforcement of learned behaviors. These processes are generally best understood at the level of relatively temporally proximal events such as receiving a reward of praise, money, or food, close to the time of the stimulus. However, the realization of accomplishing a goal or the satisfaction of making a successful step toward the goal can be equally rewarding.

- Visualization: The act of visualization engages not only the early and higher-order visual thalamocortical pathways of the human brain, but also provides an opportunity for the development and refinement of internal representations of solid and complex objects along with their relative location in space. Although learning is routinely considered a process that occurs in response to certain events in the outside world (stimuli that might include semantic information that is taken in by reading or listening to a lecture or watching a procedure, for example), the neuronal networks that assemble the incoming information and construct memories shouldn't "care" about the source (whether externally or internally generated) of the triggering inputs, as long as the requisite cellular and circuit signaling processes are accessed. Regarding e-REAL, it's very relevant that both externally and internally generated activity in the brain from thoughts, visualization, evocation of other memories and emotions, should be able to contribute to the learning process. With the rich variety of technological innovation available to e-REAL trainers, these processes can be linked in interactive ways to the learners to allow for the better use of these neural processes, and perhaps can also be applied in persons who have not developed these internalization skills sufficiently. Introspection and selfreflection are important components of any such process and can contribute to the strengthening of rehearsed actions or thoughts. In fact, recent neurobiological evidence suggests that networks of "mirror neurons" in the brain may contribute to such processes. These types of rehearsal/visualization processes also access neural circuits that implement complex decision-making algorithms that have numerous branch points and weighting functions.

- Stress: Although the consequences of stress are generally considered undesirable, there is evidence that the molecular signals associated with stress can facilitate synaptic potentiation in brain circuits involved in the formation of memory, and can also be behaviorally reinforcing to learning. However, particularly high levels of stress can have the opposite effect. The interactive and immersive e-REAL learning setting may be judiciously employed to moderately engage the stress system on a more regular basis. Such a format provides individual accountability to peers and teachers in a group setting, which gives more insight into the learner's thought processes than would typically occur through more traditional and brief an- swer-based learning settings where the learner's reasoning processes are not shared.

- Fatigue: It is important to have appropriate downtime between intense problem-solving sessions, or group venues, where detailed quantitative reasoning skills are required. Such downtime permits consolidation or reinforcement away from the formal teaching process.

- Multitasking: It is important that educational methods integrate multimodal information relevant to the topic; this encourages engagement of relevant converging informational mechanisms by enhancing rather than dispersing attention. Reinforcement of concepts and facts in a temporally proximal domain through varied media engages processes that facilitate abstraction, and the construction of integrated frameworks of knowledge for the synthesis, and future accessibility of information for recall and implementation. The same technologies that enable multitasking during learning can be used to enable and tap into the intrinsic neural processes that enhance the learning process.

- Individual Learning Styles: It is well appreciated that there are many different types of learners and learning strategies. Individuals have various types of intelligence, and show differences in the types of learning that they employ best. Some are particularly adept at integrating lecture material, others are better at obtaining the material independently through reading, and others benefit from various forms of visualization, or interactive use of the material. The neural responses of these different individuals also show variability, and that is the rationale for embracing multiple learning styles to provide opportunities for all learners to be most effectively reached, to provide opportunities for positive feedback and successes, and to reinforce information with multimodal convergent strategies, even for those who excel equally with all approaches.

- Active Involvement: There is considerable support for active involvement when learning skills and concepts are involved. A laboratory and simulation environment such as e-REAL is a rich venue for the learning process and for storing information into memories based on those experiences. In other words, doing is learning. And success at doing/learning builds confidence, as has been shown by recent neurobiological studies of human performance during episodic retrieval of remembered information.

- Revisiting Information and Concepts Through Multimedia and Sensory Processes: Decoding and analyzing outside information for developing internally generated representations of information to learn and to consolidate information is recommended. Moreover, these processes use uni-sensory, as well as multisensory integration areas of the brain with individual variations in the relative contributions of these modalities. Multiple teaching approaches addressing the same information using different sensory processes are likely to enhance the learning process, potentially bringing more neural hardware to bear to process and store information.

In brief: Revisiting information and concepts through multimedia and sensory processes, grasping different 
individual cognitive styles, active involvement and visualization, as well as repetition, reward and reinforcement, appropriate levels of stress and fatigue depending on the learners and training aims, are tried and effective teaching strategies.

\section{TESTING E-REAL: EVIDENCE FROM THE FIELD}

Summarizing the evidence from the field, after the first cycle of experimental programs, we can conclude that the e-REAL learning setting improves people's overall results - this is measured through selected key performance indicators (KPIs) with an average of $48 \%$. Results - and related KPIs - are those regarding the performance in the workplace, because the design, scoring and interpretation of assessment centers commonly focuses on job-relevant dimensions.

We primarily monitored a cluster of skills related to behavioral outcomes: active listening, asking open questions, knowledge sharing by metaphors easily understandable within the classmates' group; in addition, we monitored the ability to imitate relevant gestures in order to manipulate technical equipment.

The monitoring methodology was the assessment center (ACs). Both of the authors of this paper were directly involved as assessors, within a team comprised of four assessors.

We assessed people - focusing on the same corecompetences - before the delivery in the e-REAL lab, and during a follow-up (usually 2 weeks after the delivery). During the period of January 2012-June 2014, our experimental testing involved 64 people who voluntarily attended 4 different programs (on negotiation, scenario thinking, knowledge sharing in a matrix organization, and safety on an oceanic oil exploitation platform). Each program involved 2 different groups, comprised of 8 people each. For each program, one group was involved within an e-REAL lab (4 projected surfaces with multimedia contents available during that time +2 iPads available during the sub-groups activity), with a second group attending a more traditional learning setting (a classroom with only one projected surface with multimedia contents made available depending on the instructor's decision).

The same instructor was involved both within e-REAL and in the traditional classroom. The "deliverables" were the same. The working language was English (better: "global English") and 100\% of the attendees did not have English as their mother-tongue, to avoid inequality. The enrolled attendees' fluency in English was tested before kicking-off as an upper-intermediate.

So, we can say that $48 \%$ is an average overall result reached after having attended an e-REAL program, and that means that it is really effective and can be seen as a "killer application" if compared with the more traditional learning settings.

To conclude, we can say that e-REAL is an innovative learning methodology highly effective mainly with regards to the following different aspects:

a) Training Duration and Effectiveness: All e-REAL programs are designed to facilitate the learning process: assessment of learning outcomes proves that 3 hours in the e-REAL immersive lab corresponds to 8 hours in a traditional training classroom. b) Situated Learning: In the e-REAL labs, learners are immersed - mind and body - in realistic training scenarios that reflect the way knowledge has to be sourced and shared in real life, allowing experimentation through sensing, thinking and acting for a deep learning, fostering at the same time soft and technical skills.

c) Simplicity: Learning with e-REAL is simple. In the eREAL learning environment, all the contents are presented and visualized in a way that fosters comprehension and engages attention. Diagrams, maps, charts, images, video and data visualizations all help learners in understanding complex concepts in an easy way. e-REAL methodology allows us to link different representations of the same information (critical thinking).

d) Serious Gaming and Active Involvement: e-REAL offers an effective game-based learning environment, rising participation and a method that keeps the users focusing for longer periods of time. Learners who are actively engaged promote collaborative construction of knowledge and this allows for better memorization. Learners work toward a goal, choosing actions and experiencing the consequences of those actions along the way, making mistakes in a risk-free setting and then practice different ways to do things.

e) 360 Feedback: e-REAL provides continuous feedback during the training session through tools tracking verbal and non-verbal communication, time, movements, postures and semantics. Real time feedback gives learners a better understanding about the way they behave, increasing their awareness and offering clear guidance on how to improve their capabilities.

From an instructional design point of view, this means providing learning environments with multiple and varied resources and designing recursive fruition logics, so that the same subject can be represented by multiple, rather than singular, representations, each of which having its own form, perspective and conceptual dimension.

In summary: e-REAL is an environment that immerses the learners into an augmented, or enhanced, reality, where real life situations can be experienced (interaction with peers and trainers, tutors, facilitators, mentors): becoming part of a living, serious 3D game - not only playing within a role-play game in a classroom or interacting with an artificial scenario (as within existing e-learning), but with the added value that the lessons are learned within a real-life environment; only without the disadvantage of a negative impact in case of mistakes. Last, but not least, e-REAL enables processes aimed at fostering metacognition.

Networked knowledge societies and digital technologies are radically transforming what people learn, how they learn and where they learn. This transformation is already under way. Technology does not transform learning by itself, but only in conjunction with other social, cultural and economic factors. Knowledge is socially constructed, so learning is a process of social action, and engagement involving ways of thinking, doing and communicating. e-REAL is the ideal environment to have improved metacognition, cognitive flexibility, and the ability to self-monitor a professional performance, through the interaction between humans and technology. 
PAPER

E-REAL: ENHANCED REALITY LAB

\section{REFERENCES}

[1] J.H. Flavell, "Metacognition and cognitive monitoring: A new area of cognitive-developmental inquiry," American Psychologist, vol. 34, pp. 906 - 911, 1979. http://dx.doi.org/10.1037/0003066X.34.10.906

[2] T.A. Edison, "Advertisement for the Edison Kinetoscope," The Moving Picture News, vol. 18, p. 6, January 1913.

[3] B. Bertagni, M. La Rosa and Fernando Salvetti (eds.), Learn How to Learn! Knowledge Society, Education and Training, Angeli, Milan, 2010.

[4] F. Salvetti, Learning Environments, pp. 227-238 in F. Amicucci and G. Gabrielli, Boundaryless Learning. Nuove strategie e strumenti di formazione, Angeli, Milan, 2013.

[5] B. Bertagni, M. La Rosa and F. Salvetti (eds.), "Glocal” Working. Living and Working Across the world with Cultural Intelligence, Angeli, Milan, 2010.

[6] M. Merleau-Ponty, La nature de la perception, 1934, in Le primat de la perception et ses conséquences philosophiques, Éditions Verdier, Lagrasse, 1996.

[7] R. Harré \& G. Gillet, The Discursive Mind, Sage, Thousand Oaks, 1994.

[8] The Works of Jeremy Bentham (edited by John Bowring), vol. 4, William Tait, Edinburgh, 1843.

[9] M. Foucault, Surveiller et punir, Gallimard, Paris, 1975.

[10] M. Foucault, L'ordre du discours, Gallimard, Paris, 1971.

[11] E. Morin, La Connaissance de la connaissance, Le Seuil, Paris, 1992.

[12] L. Nummenmaaa, E. Glereana, R. Harib and J. K. Hietanend, "Bodily maps of emotions," Procedings of the National Academy of Science of the United states of America, 12-26, 2013.

[13] R. Gross, Psychology. The Science of Mind and Behaviour, Hodder, London, 2010.

[14] H. Gardner, Education for the New Century, pp. 16-19, in B. Bertagni, M. La Rosa and Fernando Salvetti (eds.), Learn How to Learn! Knowledge Society, Education and Training, Angeli, Milan, 2010.

[15] R. Gross, Psychology. The Science of Mind and Behaviour, Hodder, London, 2010.

[16] M.J. Friedlander, L. Andrews, E.G. Armstrong, C. Aschenbrenner, J.S. Kass, P. Odgen, R. Schwartzstein, T.R. Viggiano, "What can medical education can learn from neurobiology of learning?", $A c$ ademic Medicine, 86-4, 415-420, 2011.

[17] D.E. Feldman, "Synaptic mechanism for plasticity in neocortex", Annual Review of Neuroscience, 32, 33-55, 2009; M.T. Scharf,
N.H. Woo, K.M. Lattal, J.Z. Joung, P.V. Nguyen, T. Abel, "Protein synthesis is required for the enhancement of long-term potentiation and long-term memory by spaced training", Journal of Neurophysiology, 87, 2770-2777, 2002; K.M. Goedert, J. Miller, "Spacing practice sessions across days earlier rather than later in training improves performance of a visuomotor skill", Experimental Brain Research, 189, 189-197, 2008; M.R. Pagani, K. Oishi, B.D. Gelb, Y. Zhong, "The phosphatase SHP2 regualtes the spacing effect for long-term memory induction", Cell, 139, 186198, 2009.

[18] C. Zhao, W. Deng, F.H. Gage, "Mechanisms and functional implications of adult neurogenesis", Cell, 132, 645-660, 2010; D.A. Gallo, I.M. McDonough, J. Scimeca, "Dissociating source memory decisions in the prefrontal cortex: fMRI of diagnostic and disqualifying monitoring”, Journal of Cognitive Neuroscience, 22, 955-969, 2009; H. Ruge, U. Wolfensteller, "Rapid formation of pragmatic rule representations in the human brain during instruction-based learning", Cerebral Cortex, 20, 1656-1667, 2009.

[19] M.J. Friedlander, L. Andrews, E.G. Armstrong, C. Aschenbrenner, J.S. Kass, P. Odgen, R. Schwartzstein, T.R. Viggiano, "What can medical education can learn from neurobiology of learning?", Academic Medicine, 86-4, 415-420, 2011.

[20] Whereas this evidence comes from biological studies in animals that separate the induced molecular and physiological changes over intervals of seconds, such principles also may apply to longer time intervals in humans.

[21] J.P. Meriac, B.J. Hoffman \& D.J. Woehr, "A conceptual and empirical review of the structure of assessment center dimensions", Journal of Management, 40-5 1269-1296, 2014.

\section{AUTHORS}

Fernando Salvetti, is with Logos Knowledge Network, Bern, Switzerland and the University of Milan Bicocca, Milan, Italy (e-mail: salvetti@logosnet.org).

Barbara Bertagni is with Logos Knowledge Network, Bern, Switzerland and the University of Milan Bicocca, Milan, Italy (e-mail: bertagni@logosnet.org).

This article is an extended and modified version of a paper presented at ICELW 2014, the Seventh Annual International Conference on Elearning in the Workplace, held from June 11-13, 2014 in New York. Submitted 11 July 2014. Published as resubmitted by the authors 14 October 2014. 